\title{
Prunus armeniaca Leaves Extract Protects against Isoniazid and Rifampicin Induced Nephrotoxicity through Modulation of Oxidative stress and Inflammation
}

\author{
Ayman M. Mahmoud ${ }^{1 *}$, Basant M. Morsy ${ }^{2}$, Dalia S. Abdel-Hady², Reem M. Samy ${ }^{3}$ \\ ${ }^{1}$ Department of Zoology, Physiology Division, Faculty of Science, Beni-Suef University, Beni-Suef, Egypt. \\ ${ }^{2}$ Department of Chemistry, Biochemistry Division,Faculty of Science, Beni-Suef University, Beni-Suef, Egypt. \\ ${ }^{3}$ Department of Biochemistry, Faculty of Pharmacy, Beni-Suef University, Beni-Suef, Egypt.
}

*Corresponding Author: Mahmoud, A.M. Department of Zoology, Physiology Division, Faculty of Science, Beni-Suef University, Beni-Suef, Egypt. Tel: +201144168280; E-mail: ayman.mahmoud@science.bsu.edu.eg

\begin{abstract}
Nephropathy is a microvascular complication of anti-tuberculosis therapy that can disturb treatment and cause permanent kidney damage. The current study was designed to evaluate the possible protective effects of Prunus armeniaca leaves extract against isoniazid (INH) and rifampicin (RIF)-induced nephrotoxicity in rats. The experimental rats received INH and RIF at dose level of $50 \mathrm{mg} / \mathrm{kg}$, and either $100 \mathrm{mg}$ or $200 \mathrm{mg} / \mathrm{kg}$ body weight Prunus armeniaca leaves extract orally for 45 days. INH/ RIF administration induced nephrotoxicity evidenced by the histopathological alterations as well as significant $(\mathrm{P}<0.001)$ increase in serum urea, creatinine and uric acid. INH/RIF-intoxicated rats exhibited a significant increase in serum tumor necrosis factor alpha $(\mathrm{P}<0.01)$ and renal lipid peroxidation levels $(\mathrm{P}<0.001)$. Conversely, reduced glutathione content, and activity of superoxide dismutase and glutathione peroxidase were significantly declined in kidney of INH/RIF-induced rats. Concomitant supplementation with either dose of Prunus armeniaca leaves extract prevented the INH/RIF-induced biochemical and histopathological alterations. In conclusion, the present study confers new information on the protective effect of Prunus armeniaca leaves extract against anti-tuberculosis therapy-induced nephrotoxicity. Prunus armeniaca protect against INH/RIF-induced renal injury through abolishment of inflammation and oxidative stress, and potentiation of the antioxidant defense system.
\end{abstract}

Keywords: Apricot; Renal injury; Oxidative stress; Inflammation; Tuberculosis

\section{Introduction}

Tuberculosis (TB), a serious disease caused by Mycobacterium tuberculosis, is a growing international health concern ${ }^{[1]}$. It primarily affects lungs and secondarily other organs of the body ${ }^{[2]}$. The standard treatment of TB consists of a six to nine months course of antibiotics including isoniazid (INH), rifampicin (RIF), pyrazinamide (PZA) and ethambutol or streptomycin ${ }^{[3]}$. It has been reported that the use of isoniazid and its combination with rifampicin is associated with liver damage that could result in acute liver failure with a high mortality rate ${ }^{[4,5]}$. The rate of their hepatotoxicity is much higher in developing countries compared to that in developed countries, even with using the same dose schedule ${ }^{[6]}$. Although the hepatotoxic effects of the anti-tuberculosis drugs have been extensively studied, their induced nephrotoxicity have been poorly documented. The study of Mahmoud et al. ${ }^{[5]}$ demonstrated that oxidative stress is implicated in the INH-induced toxicity in rats. In addition, Lopez-Novoaet al. ${ }^{[7]}$ reported that reactive
Received Date: Aug 10, 2015

Accepted Date: Sep 01, 2015

Published Date: Sep 05, 2015

Citation: Mahmoud, A.M. Prunus armeniaca Leaves Extract Protects against Isoniazid and Rifampicin Induced Nephrotoxicity through Modulation of Oxidative stress and Inflammation.(2015) Int J Food Nutr Sci 2(2):100-105.

DOI: $10.15436 / 2377-0619.15 .033$

oxygen species (ROS) and oxidative stress represent the central key in the pathogenesis of drug-induced renal damage. Therefore, the use of antioxidants could offer protection against drug-induced renal damage.

Currently, medicinal plants are widely used in the treatment of many diseases owing their safety, cheapness and nontoxicity when compared with the synthetic drugs ${ }^{[8]}$. It has been estimated that about $80 \%$ of the world population relies on natural and botanical preparations as medicine to meet their health needs ${ }^{[9]}$. Also, the dietary intake of carotenoids, vitamins and flavonoids, which are widely dis- 
tributed in plants, could be useful in protecting against drug-induced nephrotoxicity ${ }^{[10]}$. Prunus armeniaca L. (apricot) is a fruit that has a high content of carotenoids ${ }^{[11]}$, vitamins and seleni$\mathrm{um}^{[12]}$. Since apricot contains $\beta$-carotene, polyphenols, flavonoids, and vitamins which are well-known antioxidants, there is a foundation for assuming that it may have strong antioxidant properties $^{[13]}$, and could protect against drug-induced oxidative stress. The fruits of Prunus armeniaca have been well studied in terms of their antioxidant and nephroprotective effects. However, the protective effects of the leaves extract against nephrotoxicity associated with the use of anti-tuberculosis drugs have not been documented. Therefore, the present study was designed to evaluate the protective effects of Prunus armeniaca leaves extract against INH and RIF-induced renal injury in rats.

\section{Materials and Methods}

\section{Chemicals}

INH was purchased from El Nasr Company for Chemicals and Drugs (Cairo, Egypt) and RIF was supplied by Novartis Pharma Company (Cairo, Egypt). Glutathione (GSH), pyrogallol, thiobarbituric acid (TBA) and 5,5'-dithiobis-(2-nitrobenzoic acid) (DTNB) were purchased from Sigma (USA). All other chemicals were of analytical grade and obtained from standard commercial supplies.

\section{Preparation of Prunus armeniaca Leaves Extract}

Leaves of Prunus armeniaca were collected from Alfayoum (Egypt). The samples were identified by a plant Taxonomist, and the plant leaves were air-dried in shade and separately ground to a fine powder. The powdered materials were extracted by maceration in $80 \%$ aqueous ethanol until exhaustion at room temperature. $100 \mathrm{~g}$ of each sample was soaked in $1 \mathrm{~L}$ of solvent with sonication at room temperature for $24 \mathrm{~h}$. After filtration, the filtrate was concentrated under reduced pressure in a rotary evaporator. The crude extracts were weighted and stored at $-20^{\circ} \mathrm{C}$ till used. The extract was subjected to tests for detection of the presence of tannins, alkaloids, carbohydrates and/or glycosides, and/or nitrogenous bases, flavonoids, saponins, unsaturated sterols and triterpenes ${ }^{[14]}$.

\section{Experimental Animals and Treatments}

Twenty-four male Wistar rats weighing 100-120 g were used as experimental animals in the present investigation. They were obtained from the animal house of Research Institute of Ophthalmology, El-Giza, Egypt. They were kept under observation for about 10 days before the onset of the experiment to exclude any intercurrent infection. The chosen animals were housed in plastic cages with good aerated covers at normal atmospheric temperature $\left(25 \pm 2^{\circ} \mathrm{C}\right)$ and normal $12 \mathrm{~h}$ light/dark cycle. Rats were received water and standard balanced diet ad libitum. All animal procedures were undertaken with the approval of Institutional Animal Ethics Committee of Beni-Suef University (Egypt).

Rats were divided to four groups $(\mathrm{N}=6)$ and were subjected to the following treatments:

Group 1 (Control): Served as control and were orally administered the vehicle $1 \%$ carboxymethylcellulose (CMC) for 45 days.
Group 2 (INH/RIF): Rats received INH $(50 \mathrm{mg} / \mathrm{kg}$ body weight) and RIF (50 mg/kg body weight) dissolved in water and the $1 \%$ CMC orally for 45 days.

Group 3 (INH/RIF + 100 mg Prunus armeniaca): Rats received INH (50 mg/kg body weight) and RIF (50 mg/kg body weight) dissolved in water and $100 \mathrm{mg}$ Prunus armeniaca leaves extract dissolved in 1\% CMC orally for 45 days.

Group 4 (INH/RIF + 200 mg Prunus armeniaca): Rats received INH (50 mg/kg body weight) and RIF (50 mg/kg body weight) dissolved in water and $200 \mathrm{mg}$ Prunus armeniaca leaves extract dissolved in 1\% CMC orally for 45 days.

The doses of INH, RIF and Prunus armeniaca were balanced consistently as indicated by any change in body weight over the entire period of study. By the end of the experiment, animals were sacrificed under ether anesthesia and blood samples were collected, left to coagulate and centrifuged at $3000 \mathrm{rpm}$ for $15 \mathrm{~min}$ to separate serum. Kidney samples were immediately excised and perfused with ice-cold saline. Frozen samples $(10 \%$ $\mathrm{w} / \mathrm{v}$ ) were homogenized in chilled saline and the homogenates were centrifuged at $3000 \mathrm{rpm}$ for $10 \mathrm{~min}$. The clear homogenates were collected and used for subsequent assays. Other kidney samples were fixed in $10 \%$ buffered formalin for histological processing.

\section{Biochemical Assays}

Determination of Serum Urea, Creatinine and Uric Acid:

Serum urea, creatinine and uric acid levels were assayed using reagent kits purchased from Biosystems (Spain), following the methods of Kaplan ${ }^{[15]}$, Young ${ }^{[16]}$ and Fossati et al. ${ }^{[17]}$, respectively.

\section{Determination of Serum Tumor Necrosis Factor-alpha} (TNF- $\alpha$ ): Serum levels of TNF- $\alpha$ were determined by specific ELISA kits purchased from R\&D Systems (USA), according to the manufacturer's instructions. The concentration of TNF- $\alpha$ was determined spectrophotometrically at $450 \mathrm{~nm}$. Standard plot was constructed by using standard cytokine and the concentrations for unknown samples were calculated from the standard plot (Figure 1).

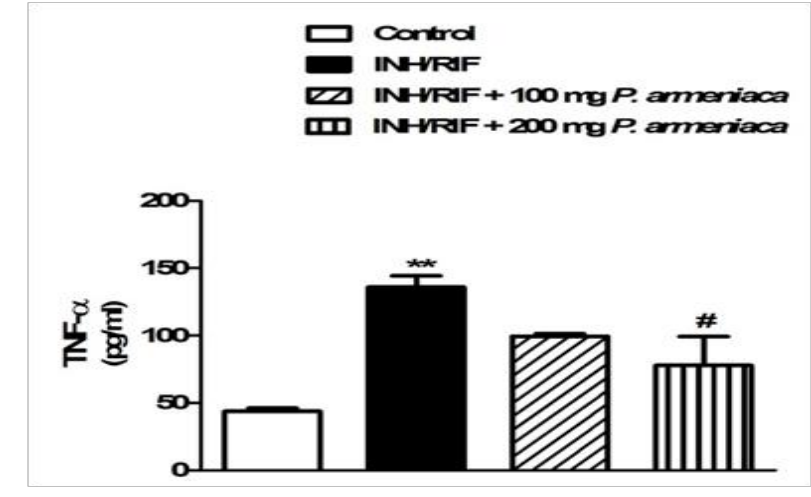

Figure 1: Serum TNF- $\alpha$ levels in control, INH/RIF and INH/RIF rats treated with $P$. armeniaca. Data are expressed as $\mathrm{M} \pm \mathrm{SEM} .{ }^{* *} \mathrm{P}<0.01$ vs control, and ${ }^{\#} \mathrm{P}<0.05$ vs INH/RIF. INH, isoniazid; RIF, rifampicin; P. armeniaca, Prunus armeniaca; TNF- $\alpha$, tumor necrosis factor alpha; SEM, standard error of mean; vs, versus.

Determination of Oxidative Stress and Antioxidant System Parameters: Lipid peroxidation, assayed as malondialdehyde (MDA), was determined in kidney homogenates according to the 
method of Preuss et al. ${ }^{[18]}$. Reduced glutathione (GSH) content was assayed according to the method of Beutler et al. ${ }^{[19]}$. Activities of superoxide dismutase (SOD) and glutathione peroxidase (GPx) were measured according to the methods of Marklund ${ }^{[20]}$ and Matkovics et al. ${ }^{[21]}$, respectively.

Histopathological Study: The kidney samples were flushed with cold saline and then fixed in $10 \%$ buffered formalin for at least $24 \mathrm{~h}$. The specimens were then dehydrated in ascending series of ethanol, cleared in xylene and embedded in paraffin wax. Blocks were prepared and $4 \mu \mathrm{m}$ thick sections were cut by a sledge microtome. The paraffin embedded sections were deparaffinized, washed and stained with hematoxylin and eosin (H\&E). The stained slides were examined under light microscope.

Statistical Analysis: Statistical analysis was performed using GraphPad Prism 5 software (GraphPad Software, San Diego, CA, USA). Results were expressed as mean \pm standard error (SEM) and all statistical comparisons were made by means of the one-way ANOVA test followed by Tukey's test post hocanalysis. A P value $<0.05$ was considered significant.

\section{Results}

Qualitative phytochemical screening revealed the presence of carbohydrates and/or glycosides, tannins, flavonoids, coumarins and triterpenes in the leaves extract of Prunus armeniaca (Table 1).

Table 1: Phytochemical content of $P$. armeniaca leave extract.

\begin{tabular}{|c|c|}
\hline Phytochemicals & P. armeniaca \\
\hline Flavonoids & ++ \\
\hline Anthraquinones & - \\
\hline Saponins & - \\
\hline Tannins & ++ \\
\hline Terpenoids & + \\
\hline Carbohydrates and/or glycosides & + \\
\hline Phlobatannins & - \\
\hline Coumarins & + \\
\hline
\end{tabular}

Data summarized in Table 2 show the effect of INH/ RIF administration and treatment with Prunus armeniaca leaves extract on renal function markers. The administration of INH/ RIF produced marked impairment of kidney function as demonstrated by the significant $(\mathrm{P}<0.001)$ increase in serum urea, creatinine and uric acid levels. Oral administration of 100 and 200 $\mathrm{mg} / \mathrm{kg}$ Prunus armeniaca leaves extract significantly decreased the elevated levels of serum urea $(\mathrm{P}<0.001)$ and creatinine $(\mathrm{P}<0.05)$ when compared with the INH/RIF control group. Similarly, Prunus armeniaca administration markedly decreased serum uric acid levels at both the $100 \mathrm{mg}(\mathrm{P}<0.001)$ and $200 \mathrm{mg} /$ $\operatorname{kg}(\mathrm{P}<0.01)$ doses.
Table 2: Serum urea, creatinine and uric acid levels in control, INH/RIF and INH/RIF rats treated with $P$. armeniaca.

\begin{tabular}{|c|c|c|c|}
\hline & $\begin{array}{c}\text { Urea }(\mathrm{mg} / \\
\mathrm{dl})\end{array}$ & $\begin{array}{c}\text { Creatinine } \\
(\mathrm{mg} / \mathrm{dl})\end{array}$ & $\begin{array}{c}\text { Uric acid } \\
(\mathrm{mg} / \mathrm{dl})\end{array}$ \\
\hline Control & $\begin{array}{c}24.39 \pm \\
1.76\end{array}$ & $\begin{array}{c}0.72 \pm \\
0.02\end{array}$ & $1.36 \pm 0.11$ \\
\hline INH/RIF & $72.4 \pm$ & $1.28 \pm$ & $3.72 \pm$ \\
& $2.87^{* * *}$ & $0.07^{* * *}$ & $0.36^{* * *}$ \\
\hline INH/RIF + 100 mg & $30.7 \pm$ & $0.73 \pm$ & $1.22 \pm$ \\
$P$. armeniaca & $3.21^{\# \#}$ & $0.05^{\# \# \#}$ & $0.07^{\# \#}$ \\
\hline INH/RIF + 200 mg & $34.8 \pm$ & $0.74 \pm$ & $1.95 \pm 0.57^{\# \#}$ \\
$P$. armeniaca & $4.68^{\# \#}$ & $0.04^{\# \# \#}$ & \\
\hline
\end{tabular}

Data are expressed as $\mathrm{M} \pm \mathrm{SEM} .{ }^{* * *} \mathrm{P}<0.001$ vs control, and ${ }^{\#} \mathrm{P}<0.01$ and ${ }^{\# \#} \mathrm{P}<0.001$ vs INH/RIF. INH, isoniazid;

RIF, rifampicin; P. armeniaca, Prunus armeniaca; SEM, standard error of mean; vs, versus.

Serum levels of TNF $\alpha$ exhibited a significant $(\mathrm{P}<0.01)$ increase in INH/RIF-intoxicated rats. Although non-significant $(\mathrm{P}>0.05)$, concomitant supplementation of the $100 \mathrm{mg} / \mathrm{kg}$ Prunus armeniaca leaves extract decreased serum TNF $\alpha$. On the other hand, administration of the higher Prunus armeniaca dose produced a significant $(\mathrm{P}<0.05)$ decrease in the serum levels of TNF- $\alpha$ when compared with the INH/RIF-administered rats.

Histopatholgical examination of the kidney sections of control rats revealed normal histological structure (Figure 2A). Conversely, INH/RIF administration produced histological changes and several lesions including atrophy of glomerular tuft, dysplastic renal tubules and inflammatory cells infiltration (Figure 2B-2D). Treatment of the INH/RIF-administered rats with either $100 \mathrm{mg}$ (Figure 2E) or $200 \mathrm{mg} / \mathrm{kg}$ (Figure 2F) Prunus armeniaca leaves extract produced marked improvement in the kidney histological structure and prevented the INH/RIF-induced alterations. Concerning lipid peroxidation, INH/RIF-intoxicated rats exhibited significantly $(\mathrm{P}<0.001)$ increased renal MDA levels as compared to their respective normal control rats (Figure 3). Treatment of the INH/RIF-induced rats with either $100 \mathrm{mg}$ or $200 \mathrm{mg} / \mathrm{kg}$ Prunus armeniaca leaves extract markedly $(\mathrm{P}<0.001)$ alleviated kidney lipid peroxidation levels.

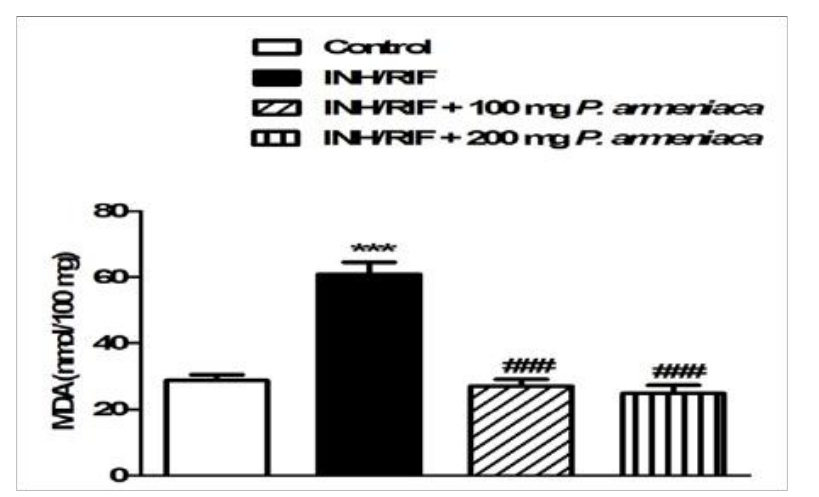

Figure 3: Lipid peroxidation in kidneys of control, INH/RIF and INH/ RIF rats treated with $P$. armeniaca. Data are expressed as $\mathrm{M} \pm \mathrm{SEM}$. ${ }^{* * *} \mathrm{P}<0.001$ vs control, and ${ }^{\# \#} \mathrm{P}<0.001$ vs INH/RIF. INH, isoniazid; RIF, rifampicin; P armeniaca, Prunus armeniaca; GSH, glutathione; SEM, standard error of mean; vs, versus. 


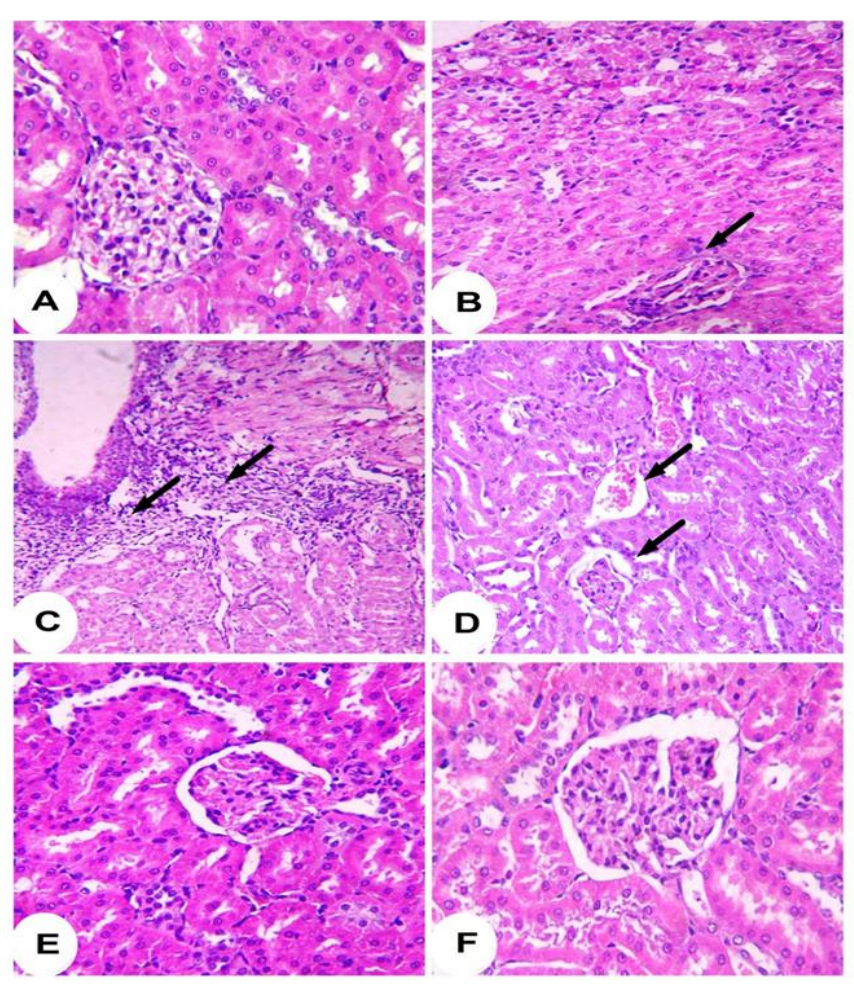

Figure 2: Photomicrographs of H\&E stained kidney sections of control (A [x400]) showing normal histological structure, INH/RIF (B [x400], $\mathrm{C}$ [x200] and D [x400]) showing dysplastic renal tubules, atrophy of glomerular tuft and inflammatory cells infiltration, INH/RIF +100 $\mathrm{mg} P$. armeniaca $(\mathrm{E}[\mathrm{x} 400])$, and $\mathrm{INH} / \mathrm{RIF}+100 \mathrm{mg}$ P. armeniaca $(\mathrm{F}$ $[\mathrm{x} 400])$ showing nearly normal renal tubules and renal corpuscles.

On the contrary, INH/RIF supplementation significantly $(\mathrm{P}<0.001)$ decreased kidney GSH content when compared with the normal control group (Figure 4). GPx activity showed a similar pattern where it was significantly $(\mathrm{P}<0.001)$ declined in the kidney $(\mathrm{P}<0.05)$ of INH/RIF-induced rats as represented in Figure 5. Similarly, SOD activity was significantly $(\mathrm{P}<0.05)$ decreased in the kidney of INH/RIF-induced rats when compared with the normal group (Figure 6). Oral supplementation of 100 $\mathrm{mg} / \mathrm{kg}$ Prunus armeniaca leaves extract potentially $(\mathrm{P}<0.01)$ ameliorated GSH content as well as activity of SOD and GPx in the kidney of INH/RIF-intoxicated rats. More or less similar, treatment with the $200 \mathrm{mg} / \mathrm{kg}$ Prunus armeniaca extract significantly $(\mathrm{P}<0.001)$ alleviated renal GSH content, and activity of SOD and GPx.
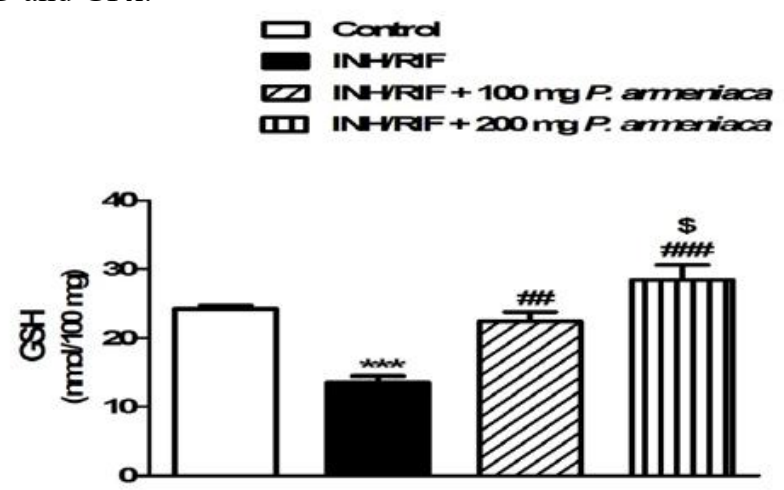

Figure 4: Reduced glutathione (GSH) in kidneys of control, INH/RIF and INH/RIF rats treated with $P$. armeniaca. Data are expressed as $\mathrm{M}$ \pm SEM. ${ }^{* * *} \mathrm{P}<0.001$ vs control, ${ }^{\#} \mathrm{P}<0.01$ and ${ }^{\# \#} \mathrm{P}<0.001 \mathrm{vs}$ INH/RIF, and ${ }^{\$} \mathrm{P}<0.05$ vs INH/RIF + $100 \mathrm{mg}$ P. armeniaca. INH, isoniazid; RIF, ri- fampicin; P. armeniaca, Prunus armeniaca; GSH, glutathione; SEM, standard error of mean; vs, versus.
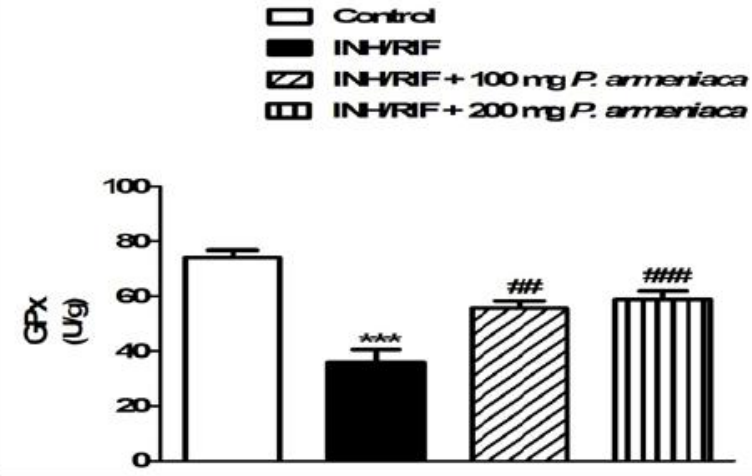

Figure 5: Glutathione peroxidase activity in kidneys of control, INH/ RIF and INH/RIF rats treated with $P$. armeniaca. Data are expressed as $\mathrm{M} \pm \mathrm{SEM} .{ }^{* * *} \mathrm{P}<0.001$ vs control, and ${ }^{\# *} \mathrm{P}<0.01$ and ${ }^{\# \#} \mathrm{P}<0.001 \mathrm{vs} \mathrm{INH} /$ RIF. INH, isoniazid; RIF, rifampicin; P. armeniaca, Prunus armeniaca; GPx, glutathione peroxidase; SEM, standard error of mean; vs, versus.

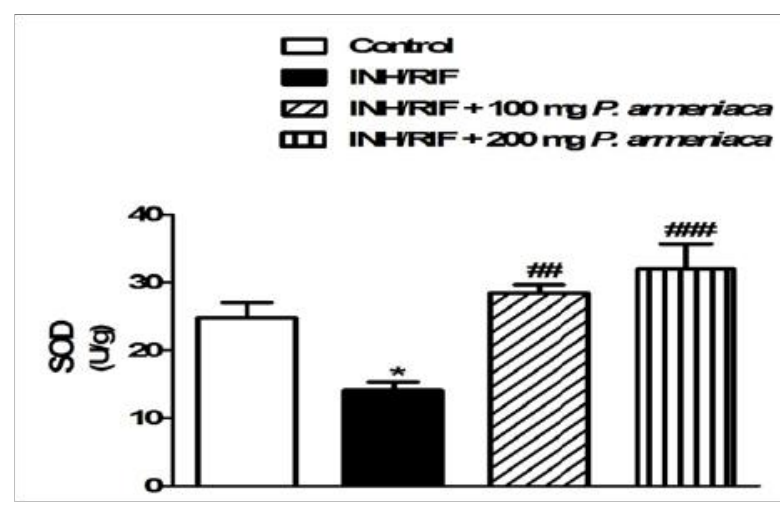

Figure 6: Superoxide dismutase activity in kidneys of control, INH/ RIF and INH/RIF rats treated with $P$. armeniaca. Data are expressed as $\mathrm{M} \pm \mathrm{SEM} .{ }^{*} \mathrm{P}<0.05$ vs control, and ${ }^{\# \#} \mathrm{P}<0.01$ and ${ }^{\# \prime \prime} \mathrm{P}<0.001$ vs INH/ RIF. INH, isoniazid; RIF, rifampicin; P. armeniaca, Prunusarmeniaca; SOD, superoxide dismutase; SEM, standard error of mean; vs, versus.

\section{Discussion}

Kidney injury is a severe complication that can disturb treatment and cause permanent kidney damage ${ }^{[22]}$. It has been reported that nephropathy is an important microvascular complication of anti-tuberculosis therapy ${ }^{[23]}$. Multiple studies have reported that oxidative stress and inflammation are implicated in drug-induced organ toxicity ${ }^{[5,24]}$. However, renal injury induced by anti-tuberculosis therapy is usually reversible and could be treated appropriately if detected early ${ }^{[23]}$. Therefore, the use of antioxidants could protect against INH/RIF-induced oxidative stress and nephrotoxicity. We designed the current study to test the hypothesis that Prunus armeniaca leaves extract could protect against INH/RIF-induced renal damage in rats through attenuation of inflammation and prevention of oxidative stress.

The present findings showed that the administration of INH and RIF has induced renal injury and glomerular dysfunction as evident by the elevated serum urea, creatinine and uric acid levels. These parameters are often regarded as reliable markers of renal damage ${ }^{[25]}$. In addition, serum creatinine has been used to estimate glomerular function and its elevation is an indicator of renal failure ${ }^{[26]}$. The elevated serum markers of renal 
toxicity markers is in agreement with the study of Hashmi et al. ${ }^{[27]}$ who reported increased serum levels of urea and creatinine in albino rabbits following administration of anti-tuberculosis drugs. INH/RIF-induced nephrotoxicity was further confirmed by the observed histological alterations such as atrophy of glomerular tuft, inflammatory cells infiltration and dysplastic renal tubules. Concomitant administration of either dose of Prunus armeniaca markedly decreased serum levels of urea, creatinine and uric acid, and potentially prevented the induced histological alterations in the kidney.

$\mathrm{TNF} \alpha$, a potent pro-inflammatory cytokine, is an important mediator of inflammatory tissue damage. It has been well documented that the immune system contributes to drug-induced nephrotoxicity, and several studies presented evidence that nephrotoxicants could induce an inflammatory response leading to organ injury ${ }^{[28]}$. INH/RIF administered rats exhibited a marked increase in serum levels of TNF $\alpha$, reflecting the degree of inflammation. These findings are in agreement with our recent study where we reported a significant increase in serum levels of pro-inflammatory cytokines in INH-induced rats ${ }^{[5]}$. On the other hand, concurrent administration of 100 and $200 \mathrm{mg}$ Prunus armeniaca leaves extract produced pronounced decline in serum $\mathrm{TNF} \alpha$, indicating its anti-inflammatory efficacy. In this context, Bhattacharjee et al. ${ }^{[29]}$ demonstrated the anti-inflammatory activity of Prunus persica leaves extract in Wistar rats.

ROS and oxidative stress have been implicated in the pathogenesis of drug-induced renal damage ${ }^{[7]}$. Long chain polyunsaturated fatty acids are abundant in the composition of renal lipids and this makes the kidney vulnerable to damage caused by $\operatorname{ROS}^{[30]}$. ROS have the ability to induce lipid peroxidation, protein damage, cellular injury, DNA fragmentation and alter the antioxidant defense system ${ }^{[31]}$. In the present study, INH/ RIF administration significantly increased the lipid peroxidation marker MDA, revealing a serious damage to kidney tissue. Daily treatment with Prunus armeniaca leaves extract markedly decreased the elevated levels of MDA, suggesting evidence that the used treatment possess a potent free radical scavenging activity. Conversely, INH/RIF-administered rats exhibited significantly declined renal GSH content as well as activity of the antioxidant enzymes SOD and GPx. GSH is a potent antioxidant which forms S-conjugates with products of lipid peroxidation ${ }^{[32]}$ and thus protects the cellular constituents. As well, SOD and GPx play a key role in protecting the body against the deleterious effects of $\operatorname{ROS}^{[33]}$. Recently, we reported that INH administration produced significant increase in MDA and NO, and marked decrease in the antioxidant defenses in rats ${ }^{[5]}$. Concurrent administration of Prunus armeniaca leaves extract markedly decreased lipid peroxidation and alleviated renal GSH content as well as activity of the antioxidant enzymes. Therefore, we assume that the nephroprotective mechanism of Prunus armeniaca against INH/RIF-induced oxidative stress is partially mediated through prevention of GSH decline and potentiation of the enzymatic antioxidant defenses. In addition, these findings provide evidence on the free radical scavenging and antioxidant activity of Prunus armeniaca leaves extract which could be attributed to the presence of active constituents of well-known antioxidant efficacy such as flavonoids, tannins and terpenoids. Previous studies demonstrated the nephroprotective effects of Prunus armeniaca fruit in radiation ${ }^{[34]}$ and methotrexate-induced ${ }^{[35]}$ kidney damage connected its protective effect to the presence of constituents such as flavonoids.

In conclusion, the present study confers new information on the protective effect of Prunus armeniaca leaves extract against anti-tuberculosis therapy-induced nephrotoxicity. Although the nephroprotective effect of Prunus armeniaca fruit has been well demonstrated, this is the first report evaluated the protective effect of its leave extract against INH/RIF-induced renal injury in rat. This renoprotective effect could be explained through the ability of Prunus armeniaca to attenuate the pro-inflammatory cytokine production, inhibit lipid peroxidative system, prevent GSH decline and enhance the enzymatic antioxidants. However, further studies are required to trace out its exact mechanistic pathways.

\section{Conflict of Interest}

The authors have declared that no competing interests exist.

\section{References}

1. Abdelaal, A., El-Ghaffar, H.A., Hosam, M., et al. Genotypic detection of rifampicin and isoniazid resistant Mycobacterium tuberculosis strains by DNA sequencing: a randomized trial. (2009) Ann Clin Microbiol Antimicrob 8: 4.

2. Ravi, V., Patel, S. S., Verma, N. K., et al. Hepatoprotective activity of Bombax ceiba Linn against isoniazid and rifampicin - induced toxicity in experimental rats. (2010) IJARNP 3(3): 19-26.

3. Tostmann, A., Boeree, M. J., Aarnouts, R. E., et al. Antituberculosis drug - induced hepatotoxicity. (2008) J Gastroenterol Hepatol 23: 192202.

4. Kumar, R., Bhatia, V., Khanal, S., et al. Antituberculosis therapy-induced acute liver failure: magnitude, profile, prognosis, and predictors of outcome. (2010) Hepatology 51: 1665-1674.

5. Mahmoud, A.M., Germoush M. O., Soliman. A.S. Berberine attenuates isoniazid-induced hepatotoxicity by modulating peroxisome proliferator-activated receptor $\gamma$, oxidative stress and inflammation. (2014) Int J Pharmacol 10: 451-460.

6. Pal, R., Vaiphei, K., Sikander, A., et al. Effect of garlic on isoniazid and rifampicin - induced hepatic injury in rats. (2006) World J Gastroenterol 12: 636-639.

7. Lopez-Novoa, J. M., Quiros, Y., Vicente, L., et al. New insights into the mechanism of aminoglycoside nephrotoxicity: an integrative point of view. (2011) Kidney Int 79: 33-45.

8. Bhawna, S., Kumar, S. U. Hepatoprotective activity of some indigenous plants. (2009) Int J Pharm Tech 1: 1330-1334.

9. Ogbera, A.O., Dada, O., Adeyeye, F., et al. Complementary and alternative medicine use in diabetes mellitus. (2010) West Afr J Med 29(3): 158-162.

10. Morales, A. I., Vicente-Sánchez, C., Sandoval, J. M., et al. Protective effect of quercetin on experimental chronic cadmium nephrotoxicity in rats is based on its antioxidant properties. (2006) Food Chem Toxicol 44(12): 2092-2100.

11. Ruiz, D., Egea, J., Tomás-Barberán, F. A., et al. Carotenoids from new apricot (Prunus armeniaca L.) varieties and their relationship with flesh and skin color. (2005) J Agric Food Chem 53(16): 6368-6374.

12. Munzuroglu, O., Karatas, F., Geckil, H. The vitamin and selenium contents of apricot fruit of different varieties cultivated in different geographical regions. (2003) Food Chem 83: 205-212.

13. Ozturk, F., Gul, M., Ates, B., et al. Protective effect of apricot (Prunus armeniaca L.) on hepatic steatosis and damage induced by carbon tetrachloride in Wistar rats. (2009) Br J Nutr 102 (12): 1767-1775. 14. Claus, E.P. Pharmacognosy $4^{\text {th }}$ edn. (1961)The Journal of New Drugs 1(5): 244.

15. Urea.K.A. Clin Chem The CV Mosby Co St Louis. (1984).

16. Young, D. S. Effects of drugs on Clinical Laboratory Tests $4^{\text {th }}$ edn. (1995) AACC Press. 
17. Fossati, P., Prencipe, L., Berti, G. Use of 3,5-dichloro-2-hydroxybenzenesulfonic acid/4-aminophenazone chromogenic system in direct enzymic assay of uric acid in serum and urine. (1980) Clin Chem 26: 227-231.

18. Preuss, H. G., Jarrell, S. T., Scheckenbach, R., et al. Comparative effect of chromium vanadium and Gymnema sylvestre on sugar-induced blood pressure elevation in SHR. (1998) J Am Coll Nutr17(2): 116-123. 19. Beutler, E., Duron, O., Kelly, B. M. Improved method for the determination of blood glutathione. (1963) J Lab Clin Mid 61: 882-888.

20. Marklund, S., Marklund, G. Involvement of the superoxide anion radical in the autoxidation of pyrogallol and a convenient assay for superoxide dismutase. (1974) Eur J Biochem 47(3): 469-474.

21. Matkovics, B., Szabo, L., Varga, I. S. Determination of enzyme activities in lipid peroxidation and glutathione pathways (in Hungarian). (1998) Laboratoriumi Diagnosztika 15: 248-249.

22. De Vriese, A. S., Robbrecht, D. L., Vanholder, R. C., et al. Rifampicin-associated acute renal failure: pathophysiologic, immunologic, and clinical features. (1998) Am J Kidney Dis 31(1):108-115.

23. Rekha, V. V. B., Santha, T., Jawahar, M. S. Rifampicin induced renal toxicity during retreatment of patients with pulmonary tuberculosis. (2005) JAPI 53: 811-813.

24. Mahmoud, A.M. Hesperidin protects against cyclophosphamide-induced hepatotoxicity by up regulation of PPAR $\gamma$ and abrogation of oxidative stress and inflammation. (2014) Can J Physiol Pharmacol 92(9): 717-724.

25. Adebisi, S. A., Oluboyo, P. O., Okesina, A. B. Effect of drug-induced hyperuricaemia on renal function in Nigerians with pulmonary tuberculosis. (2000) Afr J Med Med Sci 29 (3-4): 297-300.
26. Adeneye, A.A., Benebo, A.S. Protective effect of the aqueous leaf and seed extract of Phyllanthus amarus on gentamicin and acetaminophen-induced nephrotoxic rats. (2008) J Ethnopharmacol 118(2): 318323.

27. Hashmi, N., Muhammad, F., Javed, I., et al. Nephroprotective effects of Ficus religiosa linn (peepal plant) stem bark against isoniazid and rifampicin induced nephrotoxicity in albino rabbits. (2013) Pak Vet J 33(3): 330-334.

28. Araujo, L. P., Truzzi, R. R., Mendes, G. E., et al. Annexin A1 protein attenuates cyclosporine-induced renal hemodynamics changes and macrophage infiltration in rats. (2012) Inflamm Res 61(3): 189-196.

29. Bhattacharjee, C., Gupta, D., Deb, L., et al. Effect of leave Extract of Prunus persica Linn on Acute Inflammation in Rats. (2011) Res J Pharmacog Phytochem 3(1): 38-40.

30. Ozbek, E. Induction of oxidative stress in kidney. (2012) Int J Nephrol.

31. Nencini, C., Giorgi, G., Micheli, L. Protective effect of silymarin on oxidative stress in rat brain. (2007) Phytomedicine 14(2-3): 129-135.

32. Laurent, A., Perdu-Durand, E., Alary, J., et al. Metabolism of 4-hydroxynonenal, a cytotoxic product of lipid peroxidation in rat precision-cut liver slices. (2000) Toxicol Lett 114(1-3): 203-214.

33. Wei, X. J., Hu, T. J., Chen, J. R., et al. Inhibitory effect of carboxymethyl pachymaran on cyclophosphamide-induced oxidative stress in mice. (2011) Int J Biol Macromol 49(4): 801-805.

34. Kurus, M., Taslidere, E., Elbe, H., et al. Protective effects of Prunus armeniaca L (Apricot) on low dose radiation-induced kidney damage in rats. (2014) Turk Neph Dial Transpl 23(2): 105-111.

35. Vardi, N., Parlakpinar, H., Ates, B., et al. The protective effects of Prunus armeniaca L (apricot) against methotrexate-induced oxidative damage and apoptosis in rat kidney. (2013) J Physiol Biochem 69(3): $371-381$.
Online ISSN: 2377-0619

Journal Title: International Journal Food and Nutritional Science Journal Short Name: Int J Food Nutr Sci
Ommega Online Publishers

E-mail: editor.foodscience@ommegaonline.com Website: www.ommegaonline.org 